Radiologe $2017 \cdot 57: 923-937$ https://doi.org/10.1007/s00117-017-0310-3 Online publiziert: 16. Oktober 2017 (c) Der/die Autor(en) 2017. Dieser Artikel ist eine Open-Access-Publikation.

CrossMark

\section{I.-M. Noebauer-Huhmann' ${ }^{1}$ T. Grieser ${ }^{2}$}

'Abteilung für Neuroradiologie und Muskuloskeletale Radiologie, Universitätsklinik für Radiologie und Nuklearmedizin, Wien, Österreich

${ }^{2}$ Klinik für Diagnostische und Interventionelle Radiologie und Neuroradiologie, Klinikum Augsburg, Augsburg, Deutschland

\title{
Weichteilsarkome: Wie lassen sich posttherapeutische Veränderungen von Rezidiven unterscheiden?
}

\section{Rezidivraten und Bildgebungs- strategien für die Nachkontrolle}

\section{Rezidivraten}

Die Diagnostik und Therapie von Patienten mit Weichteiltumoren konnte in den letzten Jahrzehnten verbessert werden, auch durch interdisziplinär in Tumorboards abgesprochenes optimiertes und standardisiertes Vorgehen [10, 18, 25, 36, 92]. Dadurch konnten bei Extremitätensarkomen sehr niedrige Lokalrezidivraten von nur 4,1\% nach 5 Jahren erreicht werden, in einer anderen Studie mit extremitätenerhaltender Resektion und postoperativer Radiatio Raten von $9 \%$ nach 5 bzw. $12 \%$ nach 10 Jahren $[25,60]$. An der oberen Extremität werden etwas höhere Lokalrezidivraten beschrieben als an der unteren [30]. Bei Sarkomen im Stammbereich sind Lokalrezidive häufiger, im Becken beispielsweise treten sie in ca. $23 \%$ der Fälle auf [56], insgesamt bei Weichteilsarkomen bei ca. $17 \%$ der Patienten nach 5 und $20 \%$ nach 10 Jahren [97].

Das Risiko für ein Lokalrezidiv eines Weichteilsarkoms steigt insbesondere bei Vorliegen eines positiven Resektionsrandes nach der Operation des Primärtumors [60, 77, 88, 97], einer Studie zufolge sogar um mehr als das 3-Fache [1]. Erleidet ein Patient ein Lokalrezidiv, dann hängt auch seine weitere Prognose wesentlich davon ab, ob die Resektions- ränder bei Reoperation negativ sind [20, 49].

Höhere Lokalrezidivraten werden generell beobachtet bei einem intermediären und insbesondere hohem histologischen Tumorgrad [78, 88, 97], sowie bei großen Tumoren (insbesondere $>10 \mathrm{~cm}$ ). Ungünstige Faktoren sind des Weiteren Lokalisationen im KopfHals-Bereich und tief retroperitoneal, ein Patientenalter über 64 Jahre und bestimmte Tumorentitäten (wie das undifferenzierte pleomorphe Sarkom, das Myxofibrosarkom, der MPNST („malignant peripheral nerve sheath tumor"), und das Epithelioidsarkom; [23, 35, 36, 97]). Eine weitere Entität mit bekannt hohen Rezidivraten ist auch das hoch/dedifferenzierte Liposarkom im Retroperitoneum [71, 83].

Generell scheint zudem bei Myxofibrosarkomen und undifferenzierten pleomorphen Sarkomen eine unabsichtliche R1-Resektion häufiger vorzukommen [37], während bei Liposarkomen (abgesehen von besonderen Schwierigkeiten beim retroperitonealen Liposarkom) oder generell niedriggradigen Sarkomen häufiger eine R0-Resektion erreicht wird [49].

Bei Weichteilsarkomen hing das Gesamtüberleben in einigen Studien überwiegend vom Auftreten von Fernmetastasen ab, während Lokalrezidive hauptsächlich die lokale Tumorkontrolle beeinflussen [1]. In anderen Studien wurde jedoch auch ein Einfluss von Lokalrezidi- ven auf das Gesamtüberleben gefunden [23, 56, 60, 99].

\section{Bildgebungsstrategien für die Nachkontrolle}

Es gibt Studien, die eine Verbesserung der Überlebensrate von Hochrisikopatienten mit Weichteilsarkomen durch regelmäßige lokale Kontrolluntersuchungen nachgewiesen haben, auch durch bessere Möglichkeiten einer adäquaten lokalen Kontrolle [17]. Doch zurzeit existiert noch kein evidenzbasierter Konsens über die lokale bildgebende Nachkontrolle bei Weichteilsarkomen.

Einerseits scheinen viele Rezidive klinisch bereits durch eine tastbare Resistenz oder manchmal durch Schmerz aufzufallen [93], andererseits ist ein Tastbefund bei tiefen Lokalisationen nicht möglich oder die klinische Beurteilbarkeit durch posttherapeutische Veränderungen eingeschränkt. Einzelne Autoren raten, die bildgebende Nachkontrolle auf klinisch schlecht evaluierbare Fälle oder Hochrisikopatienten zu beschränken [14, 68].Zudem nimmt das Risiko von Weichteilsarkompatienten für ein Lokalrezidiv nach den ersten Jahren ab [19, 32, 52].

Aktuelle Leitlinien empfehlen regelmäßige Routinekontrollen mit lokaler Bildgebung und Thorax-CT (Computertomographie) bis zu 10 Jahre nach Erstbehandlung. Die Untersuchungsintervalle richten sich nach dem histologischen Grad des Sarkoms und dem 
Tab. 1 Klinische Untersuchung, lokale/regionale MRT und Thorax-CT (ohne KM)

\begin{tabular}{|l|l|l|}
$\begin{array}{l}\text { Jahr nach } \\
\text { Erstbehandlung }\end{array}$ & $\begin{array}{l}\text { Histologischer } \\
\text { Differenzierungsgrad }\end{array}$ & Untersuchungsintervall \\
\hline $1-3$ & Niedriggradig & $\begin{array}{l}\text { Basiskontrolle nach 4-6 Monaten } \\
\text { dann alle 4-6 Monate }\end{array}$ \\
\hline $3-5$ & Intermediär bis hochgradig & $\begin{array}{l}\text { Basiskontrolle nach 3-4 Monaten } \\
\text { dann alle 3-4 Monate }\end{array}$ \\
\hline$>5$ bis 10 & Alle 6 Monate & \\
\hline MRT Magnetresonanztomographie, CT Computertomographie, KM Kontrastmittel
\end{tabular}

Zeitraum seit der Primärtherapie [13, $24,57,59]$.

\section{Konsensus-Leitlinien der European Society of Musculoskeletal Radiology}

Entitätsabhängig sind eventuell weitere Untersuchungsmodalitäten indiziert (- Tab. 1; [58]).

Momentan gilt die MRT (Magnetresonanztomographie) einschließlich KM (Kontrastmittel)-gestützter Sequenzen als Goldstandard bei lokalen Nachkontrollen. In gut zugänglichen Regionen kann alternativ eine Nachkontrolle bei ausreichender Expertise mittels Ultraschall zum Ausschluss einer Raumforderung durchgeführt werden $[15,86]$.

Die PET(Positronenemissionstomographie)/CT ist einer Studie zufolge im Erkennen eines Rezidivs der MRT in Sensitivität (95\% PET/CT vs. $90 \%$ MRT) und Spezifität (95,5 vs. 97,7\%) vergleichbar, und kann eventuell bei inkonklusivem Befund der MRT hilfreich sein [66]. Sie kann in Regionen wie dem Retroperitoneum oder im $\mathrm{HNO}$ (HalsNasen-Ohren)-Bereich bei initial PETaviden Tumoren gerechtfertigt sein [13, 76] und bietet den Vorteil, gleichzeitig Fernmetastasen abzubilden.

\section{MRT-Technik}

Um den Operationssitus vollständig darzustellen, sollten die Ränder der postoperativen Narbe mittels aufgeklebten kutanen Markern gekennzeichnet werden [28].

Das Sequenzprotokoll sollte jedenfalls eine flüssigkeitssensitive Sequenz in der langen und kurzen Achse sowie eine T1wSequenz beinhalten. Eine T2w-Sequenz ohne Fettsättigung kann aufgrund des
Weichteilkontrastes zusätzliche morphologische Information über Fibrosierungen, Verkalkungen (in Zusammenschau mit Projektionsröntgen) oder Substanzablagerungen bieten.

Zumindest bei Vorliegen einer Raumforderung sollte KM gegeben werden. Die Postkontrastsequenzen sollten eine axiale fettgesättigte Sequenz post KM und eine Subtraktion beinhalten. Eine dynamische KM-Sequenz und Diffusion ist erstrebenswert, wenn verfügbar und unter Complianceaspekten zu realisieren. In Sonderfällen kann eine hämosiderinsensitive Sequenz ergänzt werden. Generell empfehlen wir ein Protokoll wie in den ESSR(European Society of Musculoskeletal Radiology)-Guidelines beschrieben [33, 59, 91].

Bei metallischen Implantaten bzw. Fremdkörpern sollten eine geringere Feldstärke, z. B. 1,5 T, gewählt und die Sequenzen adaptiert werden. Bei (zu erwartenden) deutlichen Metallartefakten sollte alternativ die Durchführung eines Ultraschalls oder eines PET/CTs überlegt werden.

Voraussetzung für die Befundung ist eine genaue Kenntnis der Anamnese und Klinik des Patienten. Diese umfasst

- Daten zur Erstdiagnose Tumorentität, histologischen Tumorgrad, Lokalisation (tief/oberflächlich, sowie den Körperabschnitt) und die Größe des Tumors,

- Kenntnis der vorangegangenen Therapien (einschließlich der Resektionsränder), auch um posttherapeutische Veränderungen einordnen $\mathrm{zu}$ können,

- Kenntnis der aktuellen Klinik: wenn möglich, sollte der Untersucher eine kurze Inspektion und Palpation des Lokalsitus durchführen zur
Erfassung einer Strahlendermatitis, subkutaner Fibrosierung oder einer Ulzeration, falls vorhanden Erfassung des Ausmaßes des tastbaren Tumors und Rekonstruktionssitus [44],

- Zusammenschau aller prä- und posttherapeutischen Vorbilder [28], einerseits, um die genaue Lage und Ausdehnung des ursprünglichen Tumors zu kennen, andererseits, da die MR-Morphologie des Rezidivtumors häufig der des Primärtumors ähnelt [28].

\section{Überblick über Therapiemodalitäten}

Weichteilsarkome sollten, wenn möglich, weit im Gesunden reseziert werden. Essenzielle Bedeutung hat somit der chirurgisch erzielte Resektionsrand.

Zur Defektdeckung bei ausgedehnteren Resektionen werden häufig myokutane Lappenplastiken verwendet [26]. Falls möglich erfolgt die Rekonstruktion mit gestielten Lappen, sodass die Gefäß-/ Nervenversorgung erhalten bleibt $[31,51$, 67].

Die Anatomie kann für den Befunder durch die Lappenplastiken unübersichtlicher werden. Zur radiologischen Orientierung daher ein kurzer Überblick über typische neoanatomische Verhältnisse am Beispiel der unteren Extremität, wo Weichteilsarkome besonders häufig vorkommen: Am Becken und dem Oberschenkel werden als gestielte Lappen besonders die Glutealmuskulatur, der M. tensor fascia lata, der M. biceps femoris, der M. rectus femoris und distal auch der M. vastus lateralis und gracilis verwendet [51]. Im Kniebereich wird häufig der mediale oder laterale Gastrocnemiusbauch geschwenkt, bei großen Defekten eventuell kombiniert mit Verlagerung des M. soleus. In Arealen mit hoher mechanischer Belastung, z. B. der Fußsohle, kann eine Defektdeckung mit einem gut vaskularisierten neurofasziokutanen Lappen (z. B. Suralislappen) indiziert sein [67]. Für ausgedehnte Defektdeckungen oder bei eingeschränkter lokaler Gefäßversorgung können freie Lappen transplantiert werden, deren Gefäßversorgung reanastomosiert wird. Häufig wird dafür der M. rectus abdo- 
Hier steht eine Anzeige.

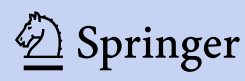


minis oder latissimus dorsi verwendet [51].

Zusätzlich zur weiten Resektion (wenn möglich extremitätenerhaltend) werden hochmaligne Sarkome in der Regel nachbestrahlt. Bei bestimmten Indikationen erfolgt eine neoadjuvante Radiatio. Der Abstand zur Operation beträgt jeweils ca. 4-6 Wochen [22, 40, $64,79,96]$. Niedrigmaligne Sarkome werden zumindest nachbestrahlt, wenn der Sicherheitsabstand der Resektion weniger als einen Zentimeter oder marginal ist und keine Nachresektion geplant ist $[16,45]$. Die Wahl der zeitlichen Abfolge hat prinzipiell keinen Einfluss auf die lokale Tumorkontrolle, Metastasierungsrate oder das krankheitsbedingte Gesamtüberleben, zumeist wird (außer bei anatomisch schwer weit $\mathrm{zu}$ resezierenden oder primär nicht resektablen Tumoren) postoperativ (adjuvant) bestrahlt $[40,64,98]$. Lokal ergeben sich durch die Therapieabfolge unterschiedliche Vor- und Nachteile (siehe auch im nächsten Abschn. unter „Posttherapeutische reguläre Veränderungen und Komplikationen“):

Die präoperative Radiatio wird in geringerer Dosis (50 Gy) durchgeführt. Das Tumorzielvolumen (GTV) wird auf den in der Bildgebung sich darstellenden Tumor definiert. Das klinische Zielvolumen (CTV) beträgt wenige Zentimeter $(2-5 \mathrm{~cm})$. Durch die präoperative Bestrahlung können inoperable Tumoren operabel werden $[4,11,63]$.

Postoperative Bestrahlung schließt das gesamte Operationsgebiet ein. Die Zielvolumina sind somit deutlich größer als bei der präoperativen Bestrahlung. Die Definition der Bestrahlungszielvolumina ist durch die veränderte Anatomie schwieriger. Höhere Bestrahlungsdosen können jedoch, abhängig von der Lokalisation des Tumorbettes und des Operationsstatus (marginale Operation, Operation weit im Gesunden), mit individuellen Dosen (50 Gy im Operationsgebiet, 60-66 Gy im Tumorbett) im Operationsgebiet angewandt werden.

Wenn möglich sollten die Bestrahlungsdosen bei definitiver Radiatio inoperabler Patienten lokal gesteigert werden (>60 Gy), um eine gute lokale Kontrolle zu erzielen [41].

Radiologe 2017·57:923-937 https://doi.org/10.1007/s00117-017-0310-3

(c) Der/die Autor(en) 2017. Dieser Artikel ist eine Open-Access-Publikation.

\section{I.-M. Noebauer-Huhmann - T. Grieser \\ Weichteilsarkome: Wie lassen sich posttherapeutische Veränderungen von Rezidiven unterscheiden?}

\section{Zusammenfassung}

Die Erkennung von Weichteilsarkomrezidiven und ihre Differenzierung von posttherapeutischen Veränderungen sind komplex. Der Beitrag soll dem klinisch tätigen Radiologen helfen, lokale Nachkontrollen systematisch zu beurteilen. Voraussetzungen sind einerseits die genaue Kenntnis der klinischen und therapeutischen Anamnese und der aktuellen klinischen Situation sowie andererseits eine adäquate Untersuchungstechnik, für die Empfehlungen gegeben werden, und ein Vergleich mit der initialen Bildgebung. Der Beitrag gibt einen Überblick über Rezidivhäufigkeiten und Therapiemodalitäten wie der Operation, Bestrahlung und Chemotherapie. Er beschreibt das MR(Magnetresononanz)-tomographische Spektrum regulärer posttherapeutischer
Veränderungen im zeitlichen Ablauf und geht auf therapieassoziierte Komplikationen ein. Diese umfassen akute Komplikationen, wie Serome, Hämatome oder Infektionen, und späte Komplikationen, wie Ödeme, Fibrosen und Gelenksteife, sowie nach variablen Intervallen auftretende Pseudotumoren. Diesen Veränderungen gegenübergestellt wird das Erscheinungsbild von Rezidiven und strahlenassoziierten Sarkomen. Es werden insbesondere MR-tomographische Kriterien vorgestellt, die helfen können, posttherapeutische Veränderungen von Rezidiven besser zu unterscheiden.

Schlüsselwörter

Serom · Radiochirurgie · Ödem · Hämatom · Leitlinien

\section{Soft tissue sarcoma: how can posttreatment alterations be distinguished from recurrences?}

\begin{abstract}
The recognition of recurrent soft tissue sarcomas and the differentiation from posttreatment alterations is complex. This article aims to assist the clinical radiologist in the systematic evaluation of local follow-up imaging in soft tissue sarcoma patients. Soft tissue sarcomas encompass multiple entities with different recurrence rates and follow-up intervals. Approved and up to date recommendations are provided, including imaging techniques. The past medical history of the patient, the clinical situation and previous therapies should be known in detail, including surgery, radiation therapy and chemotherapy. Previous imaging results should be consulted, if available. This article describes the time-dependent imaging spectrum of local post-therapeutic as well
\end{abstract}

Die Chemotherapie, üblicherweise mit Doxorubicin und Ifosfamid, gehört nicht zur routinemäßigen Behandlung von Weichteilsarkomen. Bei welchen Patienten eine zusätzliche neoadjuvante oder adjuvante Chemotherapie die Lokalrezidivrate oder das Auftreten von Metastasen vermindert, und insbesondere, bei welchen Patienten dadurch das rezidivfreie Überleben oder Gesamt- as local treatment-related complications. These include early complications, such as seromas, hematomas and infections, as well as late complications, including edema, fibrosis and joint stiffness, and also inflammatory pseudotumors, which may occur after variable time intervals. The imaging appearance of local recurrent and radiation-associated sarcoma are elucidated. In particular, magnetic resonance imaging (MRI) criteria are provided, which may help in differentiating post-therapeutic alterations from recurrent soft tissue sarcomas.

Keywords

Seroma - Radiosurgery - Edema - Hematoma . Guidelines

überleben verbessert wird, ist noch nicht endgültig geklärt $[9,95]$.

Vermutlich profitieren insbesondere Patienten mit großen Grad-III-Extremitätensarkomen von einer chemotherapeutischen Behandlung [27].

Die chemotherapeutische Behandlung ist bei Lokalrezidiven möglichst in Kombination mit einer erneuten radikalen Operation durchzuführen und bei 

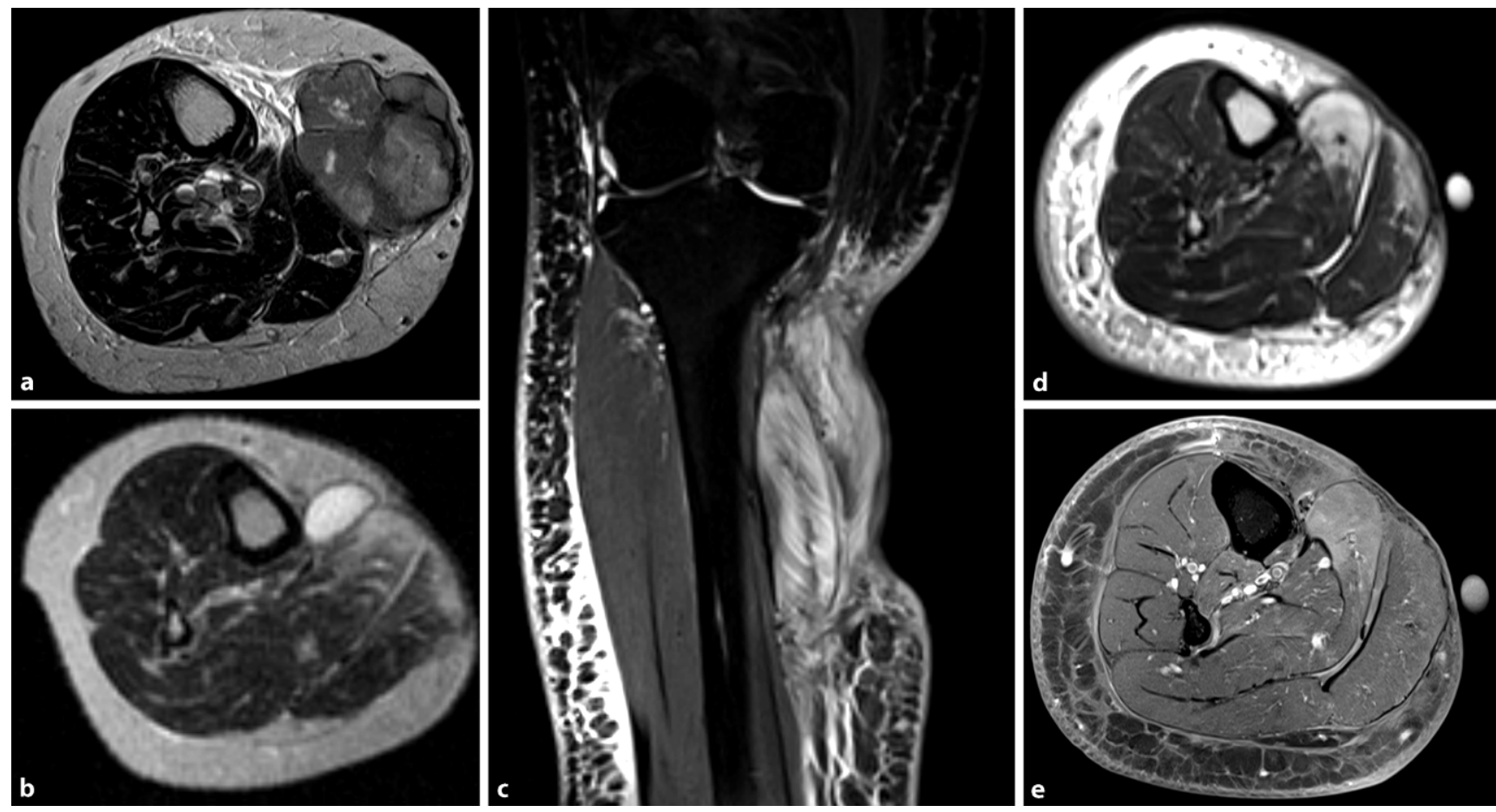

c

Abb. 1 ॥ 77-jährige Patientin mit pleomorphem Sarkom am rechten Unterschenkel, teils epi-, teils subfaszial mit breitem Konnex zum medialen Bauch des M. gastrocnemius, intraoperativ ohne Muskelinfiltration. T2-gewichtete axiale Sequenz vor (a) und nach (b) weiter Resektion, Spalthautdeckung. Dreißig Tage postoperativ in der Bestrahlungsplanung (durch Prof. Dieckmann) kleines flüssigkeitsäquivalentes Serom; Muskelödem. In der zweiten posttherapeutischen Kontrolle 8 Monate nach Operation zeigen sich auf der koronaren STIR(,,short TI inversion recovery“)-Sequenz (c), der T2-gewichteten axialen (d) und der T1-gewichteten axialen Sequenz nach Kontrastmittelgabe mit Fettunterdrückung (e) der postoperative Defekt, ein deutliches Muskelödem mit erhaltener Muskelfiederung, ein sehr schmales Serom zwischen medialem Gastrocnemiusbauch und M. soleus, ein diffuses Weichteilödem v.a. im bestrahlten Volumen und eine Vernarbung/Fibrosierung subkutan und kutan

metastasierten Patienten die Methode der Wahl.

\section{Posttherapeutische reguläre Veränderungen und Komplikationen}

\section{Reguläre posttherapeutische Veränderungen des Weichteil- gewebes: „Ödem", entzündliche Gewebereaktion und Heilung, Fibrosen/Narben}

Während des regulären Heilungsprozesses ist das Gewebe im Operationssitus zunächst durch Granulationsgewebe und eine diffuse MR-tomographisch ödemäquivalente Gewebsdurchtränkung signalalteriert. Diese Veränderungen können nach zusätzlicher Radiatio noch verstärkt sein und länger persistieren (s. unten) [81].

Ist das Gewebe diffus ödemäquivalent signalalteriert, die Architektur der Muskulatur jedoch erhalten mit allseits sicht- barer Muskelfiederung auf T1w („Textur"- oder „Fiederungszeichen"), dann ist ein Tumorrezidiv eher unwahrscheinlich (• Abb. 1; [6, 81, 90]).

Postoperativ entzündlich alteriertes Gewebe oder Fibrose können raumfordernd sein, weisen in der dynamischen KM-Sequenz jedoch fast nie ein arterielles Enhancement auf (Spezifität von $97 \%$ für Rezidiv) [33].

Zusätzlich bestrahltes Weichteilgewebe ist deutlicher signalalteriert [29], zunächst mit sehr variablem ödemäquivalenten Signal. Dieses verstärkt sich im Verlauf und ist ca. 12-18 Monate nach Bestrahlung mit Photonen am deutlichsten. Posttherapeutisch normalisiert sich das Signal bei ca. $50 \%$ der Patienten innerhalb von 2-3 Jahren. Nach Neutronenbestrahlung dagegen wird das Maximum der Veränderungen bereits nach ca. 6 Monaten erreicht. Allerdings normalisiert sich das Signal nur bei weniger als $20 \%$ der Patienten, und auch dies erst nach ca. 3-4 Jahren [75].
Ein optischer Eindruck von der klinischen Schwere kutaner Veränderungen wie Zellulitis oder Ulzerationen kann hilfreich in der Bildbeurteilung tiefer gelegener Veränderungen sein.

Das subkutane Gewebe zeigt typischerweise eine gitterartig oder trabekulär verteilte flüssigkeitsäquivalente Signalalteration, die Veränderungen in der Muskulatur sind dagegen diffuser. Die Gewebsarchitektur bleibt naturgemäß erhalten, die KM-Aufnahme ist sehr gering $[6,90]$. Diese diffus entzündlichen Muskelveränderungen werden bei ca. $80 \%$ der Patienten nach Operation und zusätzlicher Radiatio beobachtet. Sie bilden sich nach etwa 15 Monaten (mit einer großen Schwankungsbreite von 6 Monaten bis 9 Jahren) zurück [81].

Die Veränderungen der intermuskulären Septen persistieren deutlich länger als im Muskel oder dem Fettgewebe. Post Radiatio kommt es bei längeren Beobachtungen zur Atrophie der Muskulatur 

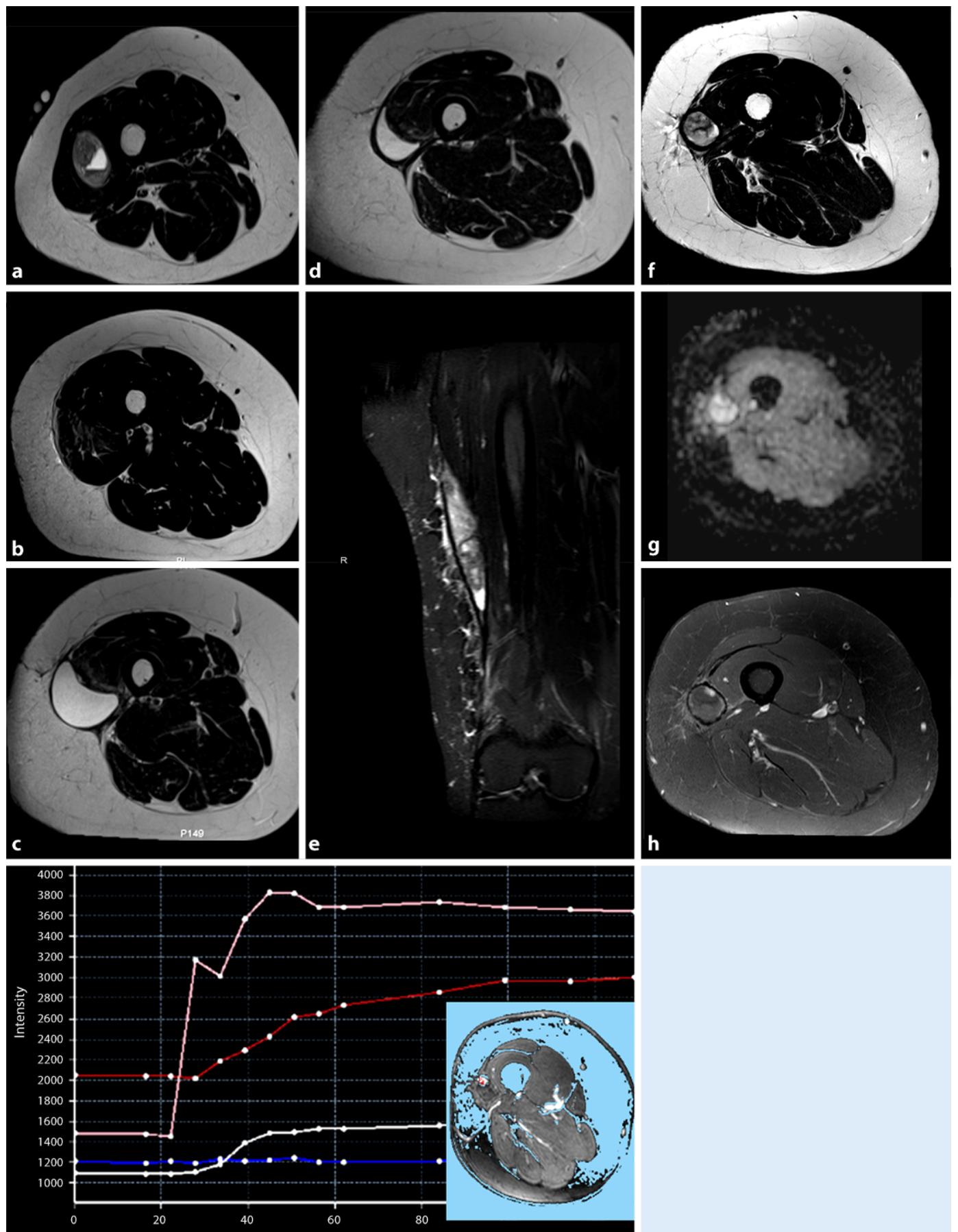

Abb. 2 ॥ 35-jährige Patientin mit biphasischem Synovialsarkom (a), das zunächst auswärts (b), und 8 Wochen zuvor weit nachreseziert wurde (c); anschließend Radiochemotherapie. Jeweils axiale T2-gewichtete Sequenz. c Serom mit flüssigkeitsäquivalentem Inhalt und gleichmäßiger, hypointenser Wand (jeweils ohne KM[Kontrastmittel]-

Aufnahme auf T1w, nicht gezeigt). Angrenzend hypointense narbige Weichgewebsverdickungen. Das Serom ist ein Jahr später etwas regredient (d). Im Verlauf zeigt sich eine zunehmende Heterogenität der Retention, jeweils ohne arterielles Enhancement. Dreieinhalb Jahre nach der weiten Resektion ist die Retention spindelförmig und im Querschnitt rundlich, sowohl in der koronalen flüssigkeitssensitiven Sequenz mit Fettunterdrückung (e) als auch axial T2w (f) inhomogen mit deutlichen hypointensen Anteilen, mit einer glatten hypointensen Wand. Keine Diffusionseinschränkung (g). Auf der axialen T1-gewichteten fettgesättigten (FS) Sequenz nach KM kleines noduläres KM-aufnehmendes wandständiges Areal (h), in der DCE-Sequenz (dynamischen Kontrastmittelsequenz) ohne arterielle KM-Anflutung (i), ansonsten kein Enhancement. Histologisch bestätigt: Serom mit Hämatombestandteilen, Debris und narbiger, gering vaskularisierter Wand. Kein Rezidiv 

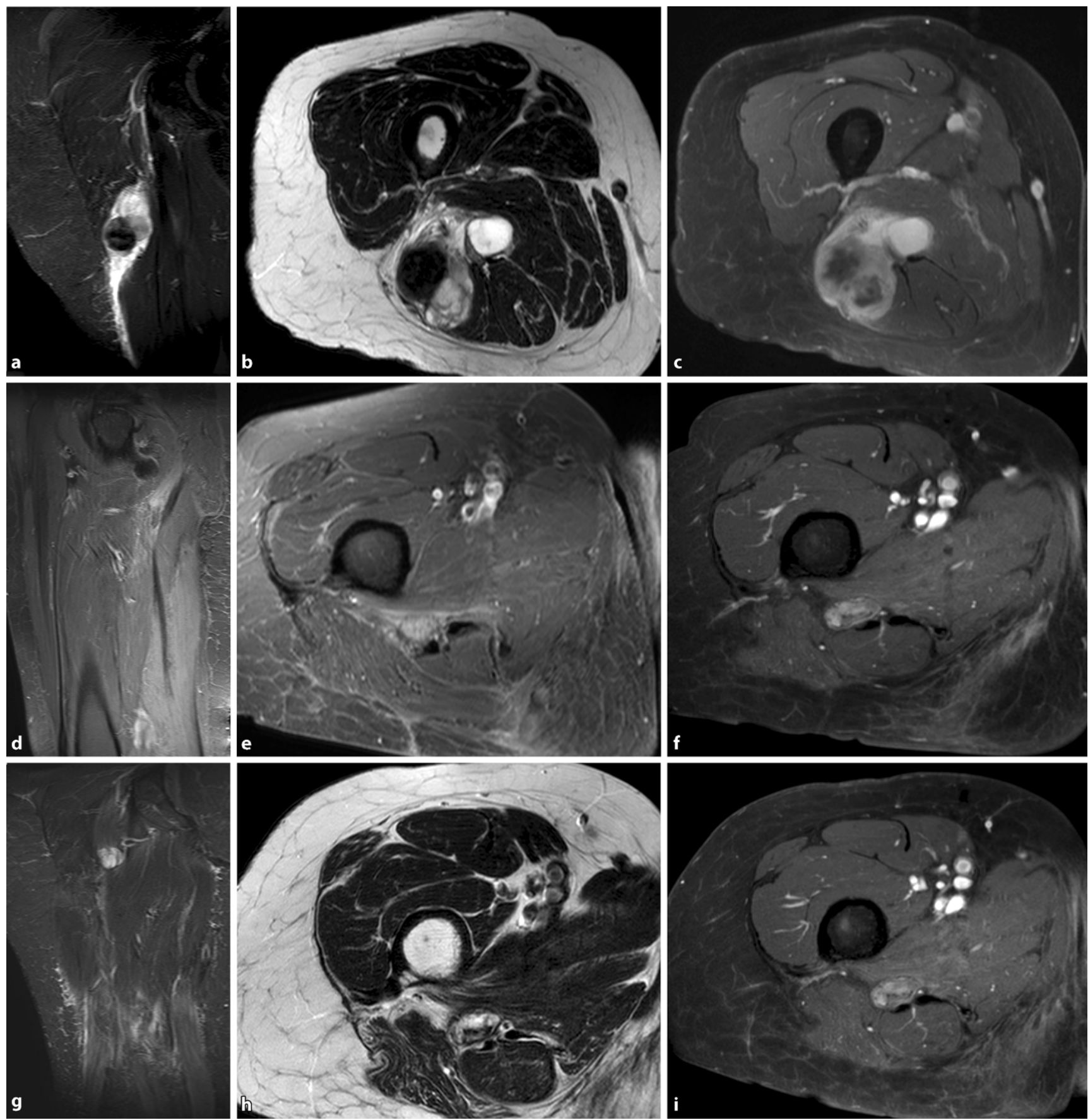

Abb. 3 \& 71-jährige Patientin mit Myxofibrosarkom am rechten Oberschenkel. a-c Koronare STIR (,short TI inversion recovery"), axiale T2w, axiale T1w fettgesättigt (FS) nach Kontrastmittel. Resektion, N.-suralis-Interponat und adjuvante Radiatio; der Situs knapp 4 Monate postoperativ, T1w FS nach Kontrastmittel sagittal und axial (d, e), mit Verdickung des Nerven im Bereich der Rekonstruktion. Im Verlauf geringe Zunahme der Verdickung bis 5 Jahre postoperativ (f). Danach stationärer Lokalbefund, axiale T2w, T1w FS nach Kontrastmittel sagittal und axial (g-i). Ausgezeichnete Funktion, keine Klinik. Nach auswärtig suspiziertem Rezidiv histologisch sekundär veränderter Nerv. Der Fall unterstreicht die Wichtigkeit der Kenntnis der Vorbefunde 

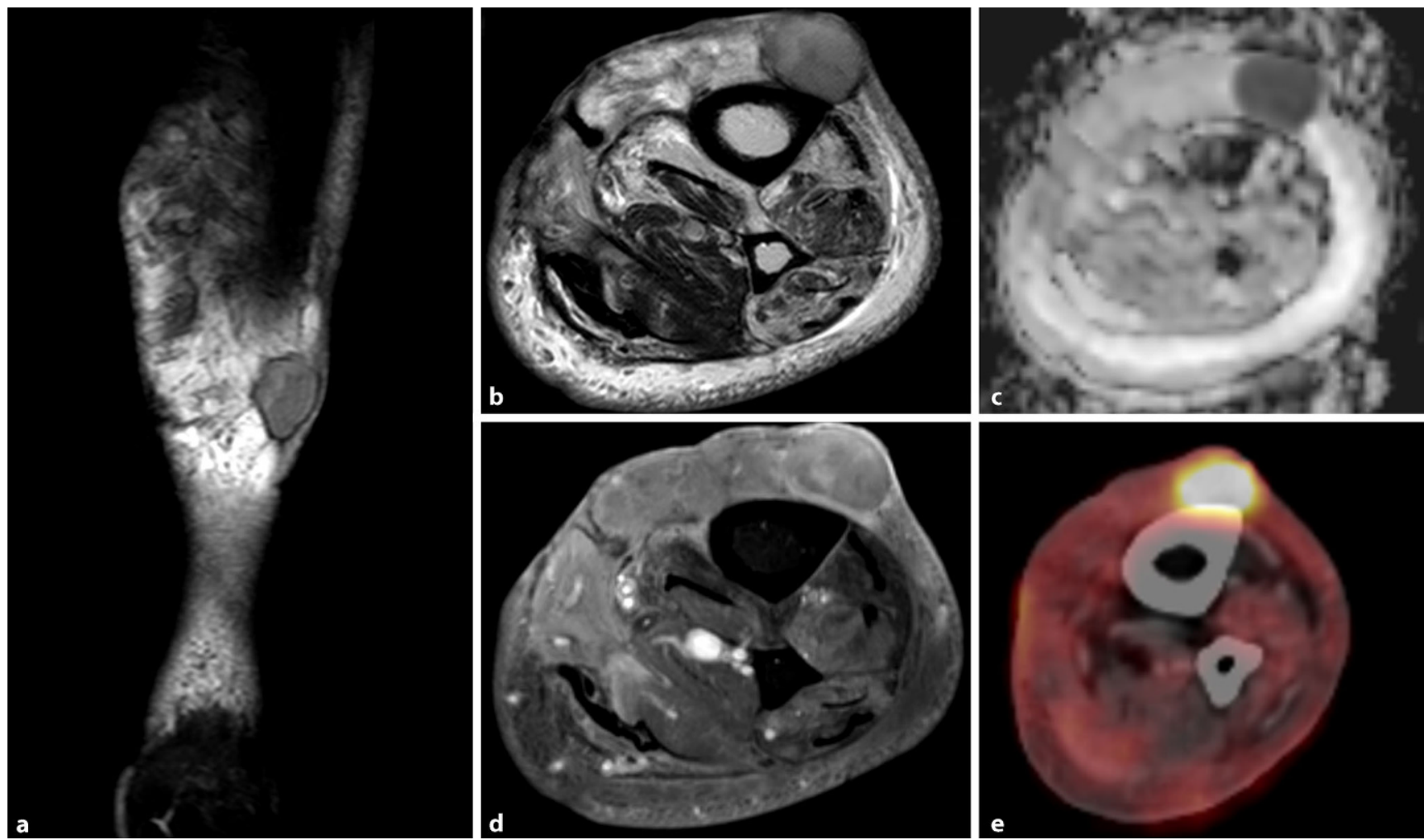

Abb. $4 \Delta$ 82-jähriger Patient mit Zustand nach auswärtiger intraläsionaler Resektionen eines Myxofibrosarkoms 1,5 Jahre zuvor, Nachresektion mit Soleusschwenklappen und Spalthauttransplantat vor 6 Monaten, Wundheilungsstörungen. In der aktuellen Nachkontrolle in der koronalen flüssigkeitssensitiven Sequenz mit Fettunterdrückung (a) umschriebener Rezidivknoten innerhalb ausgedehnter diffuser Veränderungen. Axial T2w (b) Knotenbildung mittlerer Signalintensität im Resektionsgebiet mit breitem Kontakt zur Tibia und Hautinfiltration. Deutliche Diffusionseinschränkung (c). Auf der axialen T1-gewichteten fettgesättigten Sequenz nach KM (Kontrastmittel) inhomogene KM-Aufnahme (d). In der Staging-Untersuchung mittels FDG(Fluordesoxyglucose)- PET/CT(Positronenemissionstomographie/Computertomographie) deutlich erhöhter SUV („,standardized uptake value", e). Hochgradig diffuses ödemäquivalentes Signal der Weichteile und schmale Flüssigkeitsretentionen entlang der Faszien. Der Schwenklappen ist deutlich ödematös, die übrige Muskulatur teils ödematös, teils atroph

und Fibrosierung in den Bestrahlungsvolumina. Die Dicke der intermuskulären Septen und des Fettgewebes nimmt zu [75].

Muskellappenplastiken zeigen postoperativ ebenfalls zunächst ein ödemäquivalentes Signal, das sich bei etwa einem Drittel der Patienten innerhalb von 2 Jahren normalisiert. Bei ca. $75 \%$ der Patienten besteht initial ein KMEnhancement des Lappens, das bei etwa einem Drittel der Patienten nach 1,5 Jahren nicht mehr nachweisbar ist [26].

Im Verlaufbeobachtet man häufig eine zunehmende Atrophie mit Verfettung der Muskelfasern und Abnahme des Muskelvolumens. Bei Zustand nach Radiatio und infolge einer Denervation und Abnahme der Durchblutung können diese Veränderungen verstärkt sein [26]. Die
Rolle der Bestrahlung zeigt sich auch darin, dass Muskelatrophien postoperativ nur bei knapp $8 \%$ der Patienten auftreten, gegenüber fast $50 \%$ der zusätzlich bestrahlten Patienten [81]. Die Muskelatrophie wird zusätzlich durch die fehlende Belastung aggraviert [26].

Im Endzustand ist das posttherapeutische Narbengewebe idealerweise auf allen Sequenzen hypointens [89]. Findet sich lediglich hypointenses Gewebe auf T2w, dann ist ein Rezidiv in $99 \%$ der Fälle auszuschließen [90].

Als Faustregel gilt: Größe und Komplexität des gesamten postoperativen Narbengewebes korrelieren mit der Ausdehnung des resezierten Gewebes und des gesamten Operationssitus [29].

Der mitbestrahlte Knochen zeigt ebenfalls MR-tomographisch sichtbare Signalalterationen, insbesondere nach zusätzlicher Chemotherapie. Diese meist fokalen Alterationen treten typischerweise im bestrahlten Volumen des Knochens auf. Sie können linear oder kurvilinear, nodulär oder fleckig imponieren bzw. ein Mischbild dieser Veränderungen zeigen [39].

Erste diffuse ödemäquivalente Signalalterationen im Sinne einer Osteitis im Knochenmark können bereits ca. 7-24 Tage nach Beginn der Radiatio beobachtet werden, mit einem Maximum nach ca. 9 Tagen [85]. Nach 3-6 Wochen beginnt typischerweise eine heterogene zunehmende Verfettung, die meist nach 6-8 Wochen abgeschlossen ist (an der Wirbelsäule ist manchmal der grundund deckplattennahe Wirbelkörperanteil geringer verfettet) $[7,85]$.

Hämatopoetisches Knochenmark zeigt 5-6 Jahre post Radiatio die deut- 

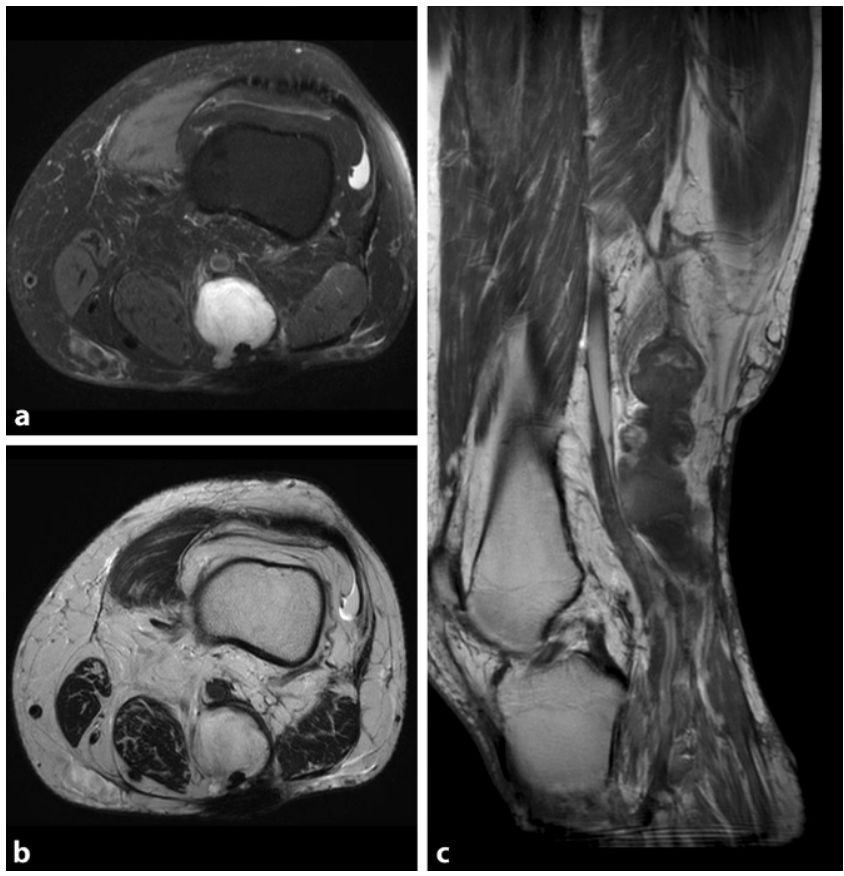

Abb. 5 A 58-jähriger Patient mit Zustand nach Myxofibrosarkom, mehrfachen Voroperationen, der sich erstmalig vorstellt. Die Rezidivknoten popliteal entlang des Gefäß-Nerven-Bündels (mit Umscheidung und Infiltration des N. popliteus) sind durch eine myxoide Tumormatrix typisch stark hyperintens auf der axialen flüssigkeitssensitiven fettgesättigten (a) und T2w-Sequenz (b), es finden sich auch hypointense Areale, die fibrotischen Tumoranteilen oder differenzialdiagnostisch angrenzendem Narbengewebe entsprechen können. Auf der sagittalen T1w-Sequenz nach Kontrastmittel heterogenes Enhancement (c); narbige Faszienverdickungen sind auf allen Sequenzen hypointens

lichsten Signalalterationen. Eine partielle Normalisierung sieht man ca. 2-9 Jahre post Radiatio und meist nur in Knochenmark, das mit weniger als $30 \mathrm{~Gy}$ bestrahlt wurde. Eine komplette Normalisierung ist bei niedrigen Dosen im Verlauf einer langen Erholungsphase von ca. 10-23 Jahren möglich. Bei lokalen Dosen über $50 \mathrm{~Gy}$ ist die Verfettung irreversibel [12].

Auf die Chemotherapie und die folgenden MR-Alterationen im Knochenmark wird hier nicht näher eingegangen.

\section{Vorkommen und Bildgebung von Komplikationen}

Von diesen regulär posttherapeutischen Veränderungen zu unterscheiden sind lokale Komplikationen. $\mathrm{Zu}$ diesen zählen neben umschriebenen postoperativen Seromen und Einblutungen auch posttherapeutische Infektionen, Gewebsnekrosen und Versagen von Lappenrekonstruktionen. Das Risiko einer postoperativen lokalen Komplikation steigt schenkel und bei Bestrahlungsdosen über 60 Gy [11].

\section{Serome}

Charakteristischerweise sind die häufig auftretenden postoperativen Serome glatt begrenzt, ihr Inhalt ist homogen flüssigkeitsisointens (• Abb. 2). Sie erscheinen bei Proteinreichtum jedoch auf T1w heller. Serome können inhomogen sein, wenn Debris enthalten ist, und selten Flüssigkeitsspiegel aufweisen. Der Serominhalt nimmt charakteristischerweise kein KM auf [21, 81]. Serome sind üblicherweise von einer meist schmalen Pseudokapsel umgeben, die mäßig und spät KM aufnimmt [21]. Serome mit kleinen nodulären relativ hypointensen Arealen im Randbereich entsprechen eventuell alten organisierten Hämatomen. Lokalrezidive innerhalb von Seromen kommen selten vor [72]. Die meisten Serome bilden sich innerhalb von 3-18 Monaten zurück [29, 81].

\section{Hämatome}

Schwieriger kann der Rezidivausschluss bei Vorliegen eines postoperativen Hämatoms sein. Das enthaltene Hämosiderin kann mittels Gradientenecho(GRE)Sequenzen durch seinen paramagnetischen Effekt („blooming“) sensitiver erkannt werden. Im Allgemeinen erscheinen Hämatome allerdings durch unterschiedliche Blutprodukte inhomogen. Gibt man KM und betrachtet danach T1-gewichtete Subtraktionsbilder (nach KM minus vor $\mathrm{KM}$ ), lässt sich verhindern, dass auf T1w hyperintense Blutprodukte als KM-Aufnahme fehlgedeutet werden. Allerdings können Hämatome auch durch Organisationsvorgänge gering $\mathrm{KM}$ aufnehmen und ihr Erscheinungsbild sich während der Hämatomorganisation ändern (- Abb. 2e-i). Organisierte Hämatome können liquifizieren [50].

Die Diffusionskapazität ist einer Studie zufolge in Hämatomen signifikant höher als bei Weichteilsarkomrezidiven oder Pseudotumoren [33].

Ein besonderes Problem stellt das sog. chronisch expansive Hämatom dar. Es erscheint inhomogen (durch eine Mischung unterschiedlicher Blutprodukte, Granulationsgewebe mit Einsprießen 

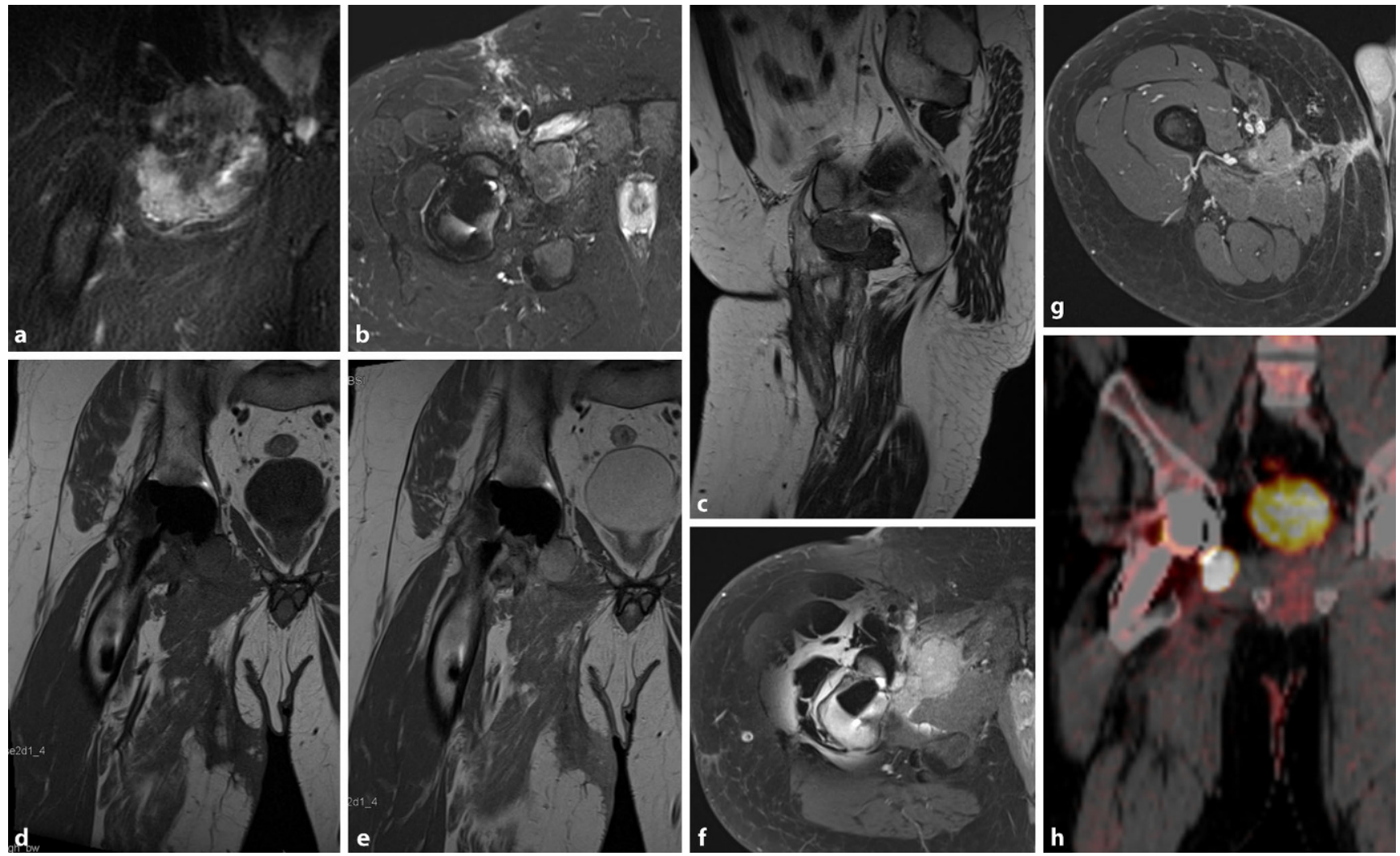

Abb. 6 \& 38-jähriger Patient mit sklerosierender, vorwiegend epithelioidzelliger Neoplasie 2 Jahre zuvor mit großem hypointensem Anteil (cor STIR, , short Tl inversion recovery", a). Nun bei Zustand nach auswärtiger Operation mit Hüft-TEP(Totalendoprothese)-Untersuchung bei 1,5 T und Verwendung von Sequenzen zur Metallartefaktreduktion, um den guten Weichteilkontrast der MRT (Magnetresonanztomographie) für die Operationsplanung nützen zu können. Die axiale STIR-Sequenz (b) und sagittale T2w-Sequenz (c) zeigen das ebenfalls großteils hypointense Rezidiv. Koronale T1w-Sequenzen vor (d) und nach Kontrastmittel (e) erlauben trotz Metallartefakten durch die TEP eine relativ gute Abgrenzung des Rezidivgewebes. Die frequenzselektive Fettsättigung der T1w-Sequenz ( $f$ ) führt naturgemäß zu stärkeren Artefakten. Weiter distal ist der Operationssitus gut beurteilbar (g). Im Ganzkörper-Staging mittels PET/CT (Positronenemissionstomographie/Computertomographie, $\mathbf{h}$ ) ist der SUV (,standardized uptake value") im Rezidiv deutlich gesteigert

von Kapillaren, entzündlichem Gewebe, nekrotischem Debris, und Fibrin; [2]) und weist meist eine Pseudokapsel (aus Fibrin, Hämosiderinablagerungen und Makrophagen) auf [50].

Die Diffusionsuntersuchung kann in der Differenzialdiagnose hilfreich sein, da der ADC (,apparent diffusion coefficient") auch in chronisch expansiven Hämatomen deutlich höher ist als in Weichteilsarkomen [62].

Das chronisch expansive Hämatom wächst langsam, vermutlich durch einen Irritationsreiz der Blutprodukte, der immer wieder zu Kapillarverletzungen und erneuten Einblutungen führt [74]. Es kann daher knotige KM-aufnehmende Anteile aufweisen. Andererseits können Rezidive einbluten, sodass der sichere Rezidivausschluss eventuell erst durch eine Biopsie möglich ist [50].

\section{Infektion/Abszess}

Infektionen nach Resektion muskuloskelettaler Tumoren kommen bei ca. 12,2 \% der Patienten mit malignen Tumoren und nur bei ca. $0,32 \%$ mit benignen Tumoren vor. Die Wahrscheinlichkeit steigt mit langer Operationsdauer, größeren Blutverlusten, präoperativer Chemotherapie (die Auswirkung einer Radiatio wurde nicht untersucht) und nach Implantaten. Bei 3-4 dieser Risikofaktoren steigt die Wahrscheinlichkeit für die Entwicklung eines Infekts auf 38,5\% [55]. Das Gewebe (beispielsweise Muskellappen) kann durch die Infektion per continuitatem zerstört werden oder durch einen erhöhten Stoffwechsel nekrotisch werden [70].

Die MR-Morphologie von Weichteilabszessen nach Tumorresektion entspricht generell der von Abszessen anderer Ursache, mit einer umschriebenen
Flüssigkeitsretention, auf T1w hypooder intermediär intens, hyperintens auf T2w ohne zentrales Enhancement, mit hypointensem, dickem irregulärem, enhancendem Randsaum [47, 84]. Allerdings ist die Differenzialdiagnose gegenüber Seromen aufgrund der ohnehin bestehenden posttherapeutischen diffusen Veränderungen erschwert. Einzelne Studien berichten über eine zumindest initial eingeschränkte Diffusion im Abszess im Gegensatz zu Seromen [38].

Wichtig ist die Kenntnis des klinischen Zustandes des Patienten und seiner Laborwerte. Zur Differenzierung gegenüber postaktinischen nichtinfektiösen Veränderungen hilft eine genaue Kenntnis des bestrahlten Volumens [8]. 

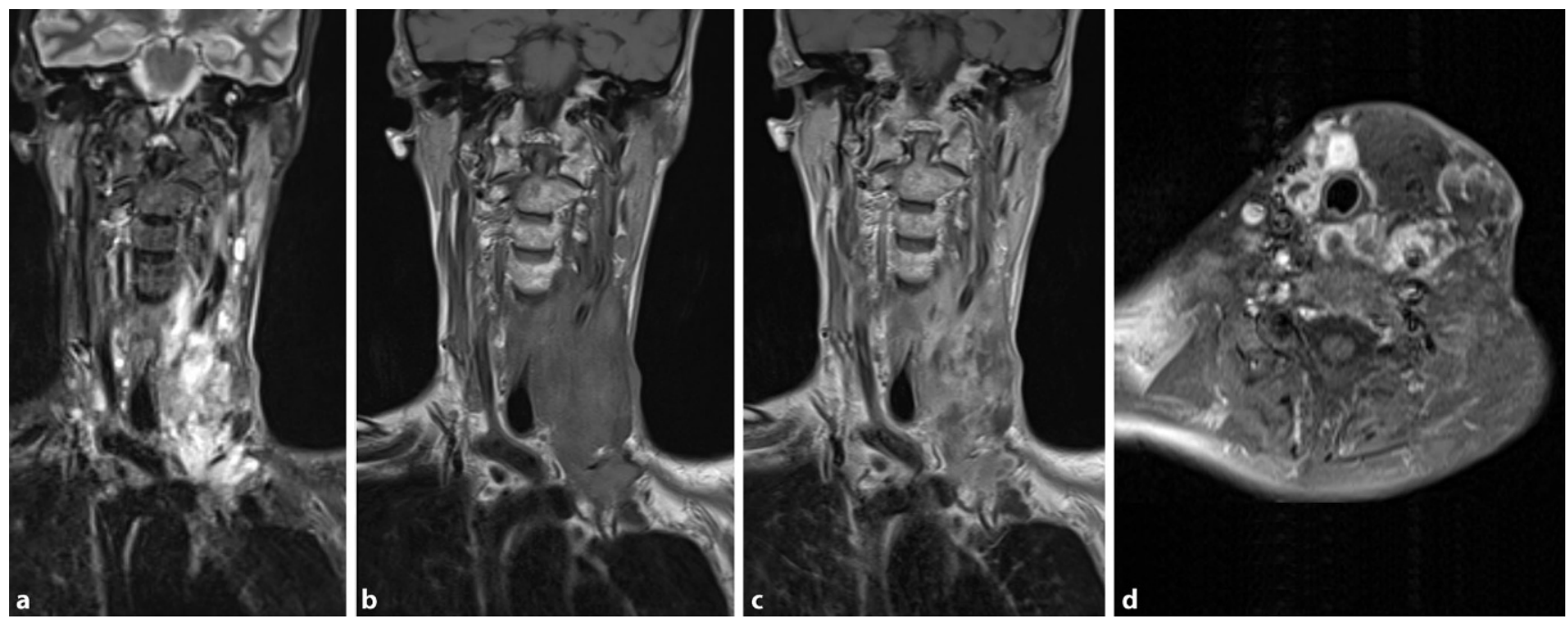

Abb. 7 × 50-jährige Patientin mit Zustand nach Radiochemotherapie bei Non-Hodgkin-Lymphom 26 Jahre vor Auftreten einer Raumforderung rechts zervikal im ehemaligen Bestrahlungsgebiet, nach mehrfachen Rezidiven inoperabel (histologisch Myxofibrosarkom). Die koronale flüssigkeitssensitive Sequenz mit Fettunterdrückung (a), T1-gewichtete Sequenz vor (b) und nach Kontrastmittel $(\mathrm{KM} ; \mathrm{c})$ zeigen den ausgedehnten sehr infiltrativ wachsenden Tumor. Anteile der wachsenden Läsion sind unter Therapie mit einem Tyrosinkinasehemmer nekrotisch (d, axiale fettgesättigte T1-gewichtete Sequenz nach KM)

\section{Inflammatorischer Pseudotumor}

Sogenannte inflammatorische Pseudotumoren sind auch nach Bestrahlung mit einer Prävalenz zwischen 5 und $12,5 \%$ und nach Strahlendosen von ca. $55 \mathrm{~Gy}$ beschrieben worden [53, 90]. Diese Pseudotumoren können sehr unterschiedlich lange nach Therapiebeginn auftreten, in einer Studie im Mittel nach 38 Monaten, mit Einzelfällen ein und 12 Jahre nach Resektion und Radiatio [53]. Sie werden als auf flüssigkeitssensitiven Sequenzen signalreiche und auf T1w im Vergleich zur Muskulatur gering signalreichere ovaläre Läsionen beschrieben, die oft unscharf begrenzt und wenig raumfordernd sind. Die KM-Aufnahme ist deutlich heterogen, jedoch im Gegensatz zu Tumorrezidiven verzögert: In dynamischen Sequenzen findet die KM-Aufnahme erst 3-9 min nach KM-Gabe statt, im Gegensatz zu Rezidiven mit typisch früher KMAufnahme nach 1-2 min [53, 90,91]. Histologisch dürften sie vaskulären Ektasien und Fibrosen entsprechen [53].

Hypertrophes Narbengewebe stellt sich als postoperativ wachsende Resistenz dar. Histologisch findet man eine erhöhte Zellularität, erweiterte Arteriolen und Kapillaren, überschießendes Kollagen, entzündliche Veränderungen und Einblutungen. Es kann daher in Einzelfällen ebenfalls T2w teils hyperintens sein [61].
Sowohl Tumorrezidive als auch Fibrosen können zu Nerveneinengungen mit Denervationsödemen und fettiger Muskelatrophie führen [81]. Nach Nervenrekonstruktionen mit einem Transplantat, beispielsweise mit einem autologen Suralisinterponat, bleibt häufig ein neurologisches Defizit. Auch bei sehr gutem klinischen Resultat können lokale Veränderungen (z. B. kleine Neurome) sichtbar sein (• Abb. 3; [73, 94]).

Auf knöcherne Komplikationen nach Bestrahlung und Chemotherapie wie Osteoporose und Insuffizienzfrakturen oder Osteonekrosen $[8,81]$ wird an dieser Stelle nicht näher eingegangen (wir verweisen hierzu auf den Beitrag über Knochentumoren in der selben Ausgabe von Der Radiologe [34]).

\section{Erscheinungsbild von Lokal- rezidiven und strahlen- assoziierten Sarkomen}

\section{Lokalrezidive}

Lokalrezidive stellen sich typischerweise als Raumforderungen oder knotige Weichteilveränderung dar ( $\bullet$ Abb.4) und sind meist hyperintens auf flüssigkeitssensitiven Sequenzen [90]. Hoch suspekt ist eine im Vergleich zur posttherapeutischen Voruntersuchung neu aufgetre- tene Läsion. Oft ähnelt das Rezidiv dem Primärtumor, so kann beispielsweise ein myxoider Tumor auf flüssigkeitssensitiven Sequenzen fast wie ein Serom aussehen (ब Abb. 5 und 6). Der Befunder sollte daher die Morphologie der aktuellen Läsion mit der des Ursprungstumors korrelieren $[28,43]$. Umschriebene hyperintense Läsionen sollten weiter mit T1gewichteten Sequenzen und Gadoliniumgabe abgeklärt werden [65], bevorzugt unter Einbeziehung von Subtraktionsbildern: Die KM-Aufnahme beweist das Vorliegen von solidem Gewebe. Besonders spezifisch ist der Nachweis einer arteriellen Anflutung im Tumor in der dynamischen KM-Sequenz, der postoperativ entzündlich alteriertes oder fibrotisches Gewebe zu $97 \%$ ausschließt [33, 91].

Als Pitfall kann Granulationsgewebe initial ebenfalls eine frühe KM-Anflutung zeigen, nach 2-6 Monaten sollte dann aber nur noch eine langsame KMAufnahme nachweisbar sein [80]. Eine posttherapeutische Basisuntersuchung erst nach 6-8 Wochen scheint daher sinnvoll, damit posttherapeutische Veränderungen bereits etwas abklingen konnten [13].

Der ADC ist idealerweise bei zellreichem Tumorgewebe niedrig ( $\bullet$ Abb. 4), jedoch bekanntermaßen stark von der 

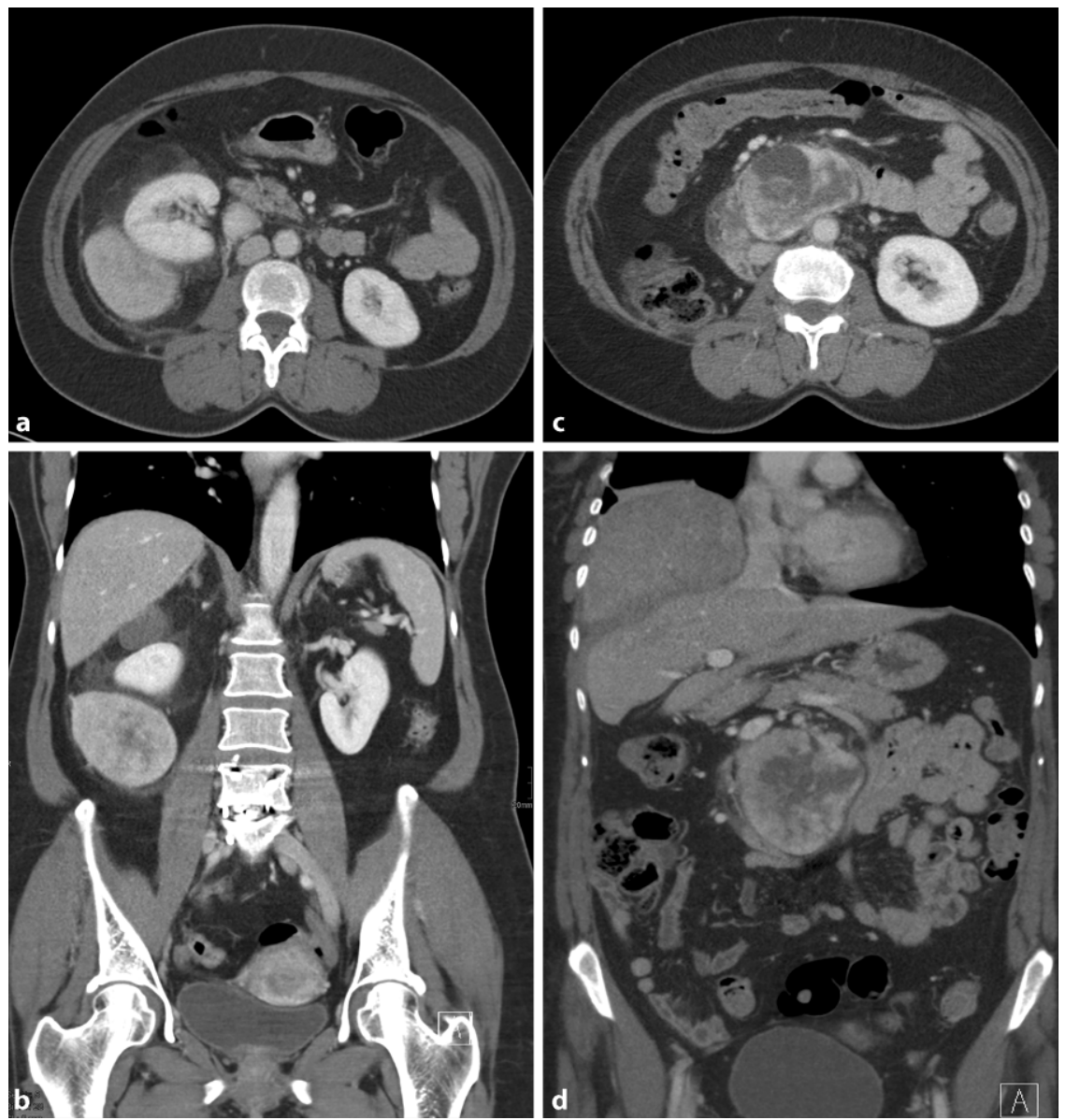

Abb. 8 × 50-jähriger Patient mit retroperitonealem hoch-/dedifferenzierten Liposarkom rechts. Kontrastmittelgestützte Computertomographie, axiale $(\mathbf{a}, \mathbf{c})$ und koronale (b,d) Rekonstruktion. Initial $(\mathbf{a}, \mathbf{b})$ liegt die rechte Niere vollständig innerhalb des Tumors, der auch hochdifferenzierte, fettdichte Anteile enthält. Sie wird von einem der dedifferenzierten weichteildichten Tumorknoten verlagert. Ein dedifferenzierter Knoten liegt zwischen Niere und V. cava. Mehrere Rezidive auch nach ausgedehnter Resektion mit Nephrektomie machen wiederholte Nachresektionen nötig. Zwei Jahre später (c,d) kommt es erneut zu einem ausgedehnten Rezidiv, das differenzialdiagnostisch auch der Dedifferenzierung eines initial hochdifferenzierten Anteils entsprechen kann

Gewebezusammensetzung abhängig, mit beispielsweise hohen Werten bei myxoiden Tumorkomponenten. Absolutwerte sind zudem stark technikabhängig.

Die Auswertung des ADC bei diesen Patienten ist daher komplex. Einerseits wurde eine Spezifitätsverbesserung in der Rezidiverkennung von $52 \%$ auf ebenfalls $97 \%$ beschrieben, wenn eine Region mit visuell niedrigem ADC vorlag, auch wenn dieses Zeichen nur bei $60 \%$ der Rezidive vorkam.

Die Diffusionskapazität von Weichteilsarkomrezidiven lag in einer Studie interessanterweise zwischen der von Hämatomen und Pseudotumoren.

Der ADC in Pseudotumoren mit KMAufnahme ist laut dieser Studie niedriger als im Tumorrezidiv, ebenso im umgebenden Subkutangewebe (letzteres vermutlich aufgrund der Pseudoinflammation um das Rezidivgewebe) [33]. Andere Studien allerdings beschreiben plausibel eine geringere Diffusion im Rezidiv als in posttherapeutischen Seromen oder ödematösen Veränderungen [5].

\section{Strahlenassoziierte Sarkome}

Strahlenassoziierte bzw. Post-RadiatioSarkome als Differenzialdiagnose sind selten $(0,03-0,2 \%)$ [69] und finden sich häufiger in den Weichteilen als im Knochen (2,3: 1) [46]. Sie treten nach einer Dosis von im Mittel ca. 50 Gy und laut Literatur [69, 82] typischerweise lange nach der Bestrahlung (im Mittel 8-15,5 Jahre). Dabei werden sehr unterschiedliche Intervalle angegeben: zwischen 2 und 65 Jahren. Die Latenzperiode ist in den Weichteilen etwas kürzer als in den Knochen [42, 48, 69, 82]. Sie äußern sich als größenprogrediente Raumforderungen [48, 82].

Die häufigsten strahleninduzierten Weichteilsarkome sind undifferenzierte pleomorphe Sarkome (bzw. die gesamte Gruppe des ehemaligen „malignen fibrösen Histiozytoms, MFH“) mit ca. $68 \%$, gefolgt vom extraossären Osteosarkom mit $13 \%$ und dem Fibrosarkom mit $11 \%$. Sie sind häufig schlecht differenziert mit entsprechendem MR-tomographischem Erscheinungsbild (• Abb. 7; [48, 69, 82]).

Bei nach längerer Latenz neu aufgetretenen Raumforderungen in den Weichteilen oder Knochendestruktionen, jeweils im Strahlenfeld, sollte differenzialdiagnostisch auch an die seltenen strahlenassoziierten Sarkome gedacht werden.

\section{Beispiele spezieller Rezidivmorphologien}

Während sich die meisten Rezidive T2w hyperintens, T1w unspezifisch ähnlich der Muskulatur darstellen, gibt es einige Tumoren mit spezieller MR-Morphologie und bekannt hohen Rezidivraten, bei denen die Berücksichtigung des Ursprungstumors hilfreich ist. Exemplarisch dafür ist das hoch-/dedifferenzierte Liposarkom, das insbesondere im Retroperitoneum vorkommt (• Abb. 8). Hier ist zur Verlaufskontrolle mit gutem Kontrast und geringen Artefakten die CT geeignet. Essenziell ist die komplette Resektion des biphasischen Tumors, also auch des (für den Chirurgen vom normalen Fettgewebe nicht unterscheidbaren und radiologisch oft nur anhand des Volumens und der Lokalisation des Fettgewebes im Vergleich zur Gegenseite suspizierten) hochdifferenzierten Anteils, der in $15 \%$ ebenfalls dedifferenzieren kann. Die Resektion abdomineller Organe, etwa der Niere, wird dafür zumeist in Kauf genommen [54, 71, 83].

In der Nachsorge (meist mittels CT) ist jede nichtlipomatöse Knotenbildung retroperitoneal und mesenteriell suspekt auf eine Dedifferenzierung. Rezidive nei- 
gen zur Invasion von Kolon, Zwerchfell, Pankreas und Dünndarm [87].

\section{Fazit für die Praxis}

Als „Faustregel“ kann in der Rezidiverkennung von Weichteiltumoren folgendes gelten: Betrachtet man zunächst eine T2-gewichtete Sequenz mit frequenzselektiver Fettsättigung, eine STIR (,short TI inversion recovery ")-Sequenz oder das Wasserbild einer DixonSequenz, dann ist ein Rezidiv zu $99 \%$ auszuschließen, wenn

- keinerlei Hyperintensität sichtbar ist (wie z. B. bei Fibrose in Narbengewebe; wobei Vorsicht geboten ist bei Läsionen wie dem Desmoid oder dem TSGCT [,tenosynovial giant cell tumor"/Tenosynovialer Riesenzelltumor] mit zumindest im Verlauf hypointensem Erscheinungsbild),

- lediglich eine „ödemäquivalente“ diffuse Hyperintensität ohne umschriebene Läsion besteht, wie bei posttherapeutischen Veränderungen oder Entzündung,

- das „Textur-“ oder „Fiederungszeichen" ohne sonstige Architekturstörung sichtbar ist,

- das Bild völlig unverändert zur Voruntersuchung bleibt.

\section{Korrespondenzadresse}

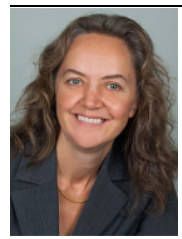

PD Dr. I.-M. NoebauerHuhmann

Abteilung für Neuroradiologie und Muskuloskeletale Radiologie, Universitätsklinik für Radiologie und Nuklearmedizin Währinger Gürtel 18-20, 1090 Wien, Österreich iris.noebauer@ meduniwien.ac.at

Danksagung. An Joannis Panotopoulos, Karin Dieckmann, Gabriele Amann, Thomas Brodowicz, Philipp Funovics und Reinhard Windhager vielen Dank für die Textdurchsicht, die Anregungen und die gute Zusammenarbeit in unserem interdisziplinären Tumorboard.

Funding. Open access funding provided by Medical University of Vienna.

\section{Einhaltung ethischer Richtlinien}

Interessenkonflikt. I.-M. Noebauer-Huhmann und T. Grieser geben an, dass kein Interessenkonflikt besteht.

Dieser Beitrag beinhaltet keine von den Autoren durchgeführten Studien an Menschen oder Tieren.

Open Access Dieser Artikel wird unter der Creative Commons Namensnennung 4.0 International Lizenz (http://creativecommons.org/licenses/by/4.0/deed. de) veröffentlicht, welche die Nutzung, Vervielfältigung, Bearbeitung, Verbreitung und Wiedergabe in jeglichem Medium und Format erlaubt, sofern Sie den/die ursprünglichen Autor(en) und die Quelle ordnungsgemäßnennen, einen Linkzur Creative Commons Lizenz beifügen und angeben, ob Änderungen vorgenommen wurden.

\section{Literatur}

1. Alamanda VK, Crosby SN, Archer KR, Song Y, Schwartz HS, Holt GE (2013) Predictors and clinical significance of local recurrence in extremity soft tissue sarcoma. Acta Oncol 52:793-802

2. Aoki T et al (1999) The radiological findings in chronic expanding hematoma. Skeletal Radiol 28(7):396-401. https://doi.org/10.1007/ s002560050536

3. Baldani EH et al (2013) Predictors for major wound complications following preoperative radiotherapy and surgery for soft-tissue sarcoma of the extremities and trunk: importance of tumor proximity to skin surface. Ann Surg Oncol 20(5):1494-1499. https://doi.org/10.1245/ s10434-012-2797-1

4. BarkleyHTJr,Martin RG, RomsdahIMM, Lindberg R, Zagars GK (1988) Treatment of soft tissue sarcomas by preoperative irradiation and conservative surgical resection. Int J Radiat Oncol Biol Phys 14(4):693-699. https://doi.org/10.1016/03603016(88)90091-0

5. Baur A, Huber A, Arbogast S et al (2001) Diffusionweighted imaging of tumor recurrences and post therapeutical soft-tissue changes in humans. Eur Radiol 11:828-833

6. Biondetti PR et al (1992) Soft-tissue sarcomas: use of textural patterns in skeletal muscle as a diagnostic feature in postoperative MR imaging. Radiology 183(3):845-848

7. Blomlie V, Rofstad EK, Skjonsberg A et al (1995) Female pelvic bone marrow: serial MR imaging before, during, and after radiation therapy. Radiology 194(2):537-543

8. Bluemke DA, Fishman EK, Scott WW (1994) Skeletal complications of radiation therapy. Radiographics 14:111-121

9. Brodowicz T, Schwameis E, Widder J et al (2000) Intensifi ed adjuvant IFADIC chemotherapy for adult soft tissue sarcoma: a prospective randomized feasibility trial. Sarcoma 4:151-160

10. Callegaro D et al (2017) Soft tissue sarcoma nomograms and their incorporation into practice. Cancer 123:2802-2820

11. Cannon CP, Ballo MT, Zagars GK et al (2006) Complications of combined modality treatment of primary lower extremity soft-tissue sarcomas. Cancer 107:2455-2461

12. CasamassimaF (1989) Blood 73(6):1677-1681
13. Catherine $C$, Roberts M, Kransdorf MJ, Beaman FD et al (2016) ACR appropriateness criteria followup of malignant or aggressive musculoskeletal tumors. J Am Coll Radiol 13(4):389-400

14. Cheney MD, Giraud C, Goldberg SI et al (2014) MRI surveillance following treatment of extremity soft tissue sarcoma. J Surg Oncol 109(6):593-596

15. Choi H, Varma DGK, Fornage BD, Kim EE et al (1991) Soft-tissue sarcoma: MR imaging vs sonography for detection of local recurrence after surgery. AJR Am J Roentgenol 157(2):353-358

16. Choong PF, Petersen IA, Nascimento AG, Sim FH (2001) Is radiotherapy important for low-grade soft tissue sarcoma of the extremity? Clin Orthop Relat Res 387:191-199

17. Chou YS et al (2012) JSurg Oncol 106:155-161

18. Coindre JM, Terrier P, Bui NB et al (1996) Prognostic factors in adult patients with locally controlled soft tissue sarcoma. A study of 546 patients from the French Federation of Cancer Centers Sarcoma Group. J Clin Oncol 14(3):869-877

19. Cormier JN, Pollock RE (2004) Soft tissue sarcomas. CACancer JClin 54(2):94-109

20. Daigeler A, Zmarsly I, Hirsch T et al (2014) Long-term outcome after local recurrence of soft tissue sarcoma: a retrospective analysis of factors predictive of survival in 135 patients with locally recurrent soft tissue sarcoma. Br J Cancer 110:1456-1464

21. Davies AM, Vanel D (1998) Follow-Up of musculoskeletal tumors I. Local recurrence. Eur Radiol 8(5):791-799. https://doi.org/10.1007/ s003300050474

22. Davis AM, O'Sullivan B, Turcotte R et al (2005) Late radiation morbidity following randomization to preoperative versus postoperative radiotherapy in extremity soft tissue sarcoma. Radiother Oncol 75:48-53

23. Eilber FC, Rosen G, Nelson SD et al (2003) Highgrade extremity soft tissue sarcomas: factors predictive of local recurrence and its effect on morbidity and mortality. Ann Surg 237:218-226

24. ESMO (2014) Soft tissue and visceral sarcomas: ESMO Clinical PracticeGuidelines for diagnosis, treatment and follow-up. Ann Oncol 25(Supplement 3):iii112-iii102

25. Felderhof JM, Creutzberg CL, Putter H et al (2013) Long-term clinical outcome of patients with soft tissue sarcomas treated with limb-sparing surgery and postoperative radiotherapy. Acta Oncol 52:745-752

26. Fox MG, Bancroft LW, Peterson JJ et al (2006) MRI appearance of myocutaneous flaps commonly used in orthopedic reconstructive surgery. AJR Am JRoentgenol 187(3):800-806

27. Frustaci S, Gherlinzoni F, De Paoli A et al (2001) Adjuvant chemotherapy for adult soft tissue sarcomas of the extremities and girdles: results of the Italian randomized cooperative trial. J Clin Oncol 19:1238-1247

28. Garner et al (2011) Posttherapy imaging of musculoskeletal neoplasms. Radiol Clin North Am 49:1307-1323

29. Garner HW, Kransdorf MJ, Bancroft LW et al (2009) Benign and malignant soft-tissue tumors: posttreatment MRimaging. Radiographics 29(1):119-134

30. Gerrand CH, Bell RS, Wunder JS et al (2003) The influence of anatomic location on outcome in patients with soft tissue sarcoma of the extremity. Cancer 97(2):485-492

31. Ghert et al (2005) The surgical and functional outcome of limb-salvage surgery with vascular reconstruction for soft tissue sarcoma of the 
extremity. Ann Surg Oncol 12(12):1102-1010. https://doi.org/10.1245/ASO.2005.06.036

32. Gibbs JF, Lee RJ, Driscoll DL, McGrath BE, Mindell ER, Kraybill WG (2000) Clinical importance of late recurrence in soft-tissue sarcomas. J Surg Oncol 73(2):81-86

33. Del Grande F, Subhawong T, Weber K, Aro M, Mugera C, Fayad LM (2014) Detection of soft-tissue sarcoma recurrence: added value of functional MR imaging techniques at 3.0T. Radiology 271:499-511

34. Grieser T, Nöbauer-Huhmann I-M (2017) Postoperative und posttherapeutische Veränderungen nach primären Knochentumoren? Radiologe. https://doi.org/10.1007/s00117-017-0304-1

35. Grobmyer SR, Brennan MF (2003) Predictive variables detailing the recurrence rate of soft tissue sarcomas. Curr Opin Oncol 15(4):319-326

36. Gronchi A, Lo Vullo S, Colombo C et al (2010) Extremity soft tissue sarcoma in a series of patients treated at a single institution: local control directly impacts survival. Ann Surg 251:506-511

37. Gundle KR et al (2017) An analysis of tumor- and surgery-related factors that contribute to inadvertent positive margins following soft tissue sarcoma resection. Ann Surg Oncol 24(8):2137-2144. https://doi.org/10.1245/s10434-017-5848-9

38. Harish $S$ et al (2011) MR imaging of skeletal soft tissue infection: utility of diffusion-weighted imaging in detecting abscess formation. Skeletal Radiol 40(3):285-294. https://doi.org/10.1007/ s00256-010-0986-1

39. Hwang S, Lefkowitz R, Landa J et al (2009) Local changes in bone marrow at MRI after treatment of extremity soft tissue sarcoma. Skeletal Radiol 38(1):11-19

40. Jebsen N, Trovik CS, Bauer HC et al (2008) Radiotherapy to improve local controlregardless of surgical margin and malignancy grade in extremityand trunk wall soft tissue sarcoma: a Scandinavian sarcoma groupstudy. Int J Radiat Oncol Biol Phys 71:1196-1203

41. Kepka L, DeLaney TF, Suit HD, Goldberg SI (2005) Results of radiation therapy for unresected softtissue sarcomas. Int J Radiat Oncol Biol Phys 63(3):852-859

42. Kim JH, Chu FC, Woodard HQ, Melamed MR, Huvos A, Cantin J (1978) Radiation-induced soft-tissue and bone sarcoma. Radiology 129:501-508

43. Kransdorf MJ, Murphey MD (2006) Radiol Clin North Am 44:463-472

44. Kransdorf MJ, Murphey MD (2006) Imaging of soft tissuetumors.In:KransdorfMJ, Murphey MD (Hrsg) Imaging of soft tissue tumors, 2. Aufl. Lippincott Williams \& Wilkins, Philadelphia, Kapitel 3:S38-79

45. Kraus-Tiefenbacher US, Van Kampen M (2015) Aktuelle Trends bei der Strahlenbehandlung nach chirurgischer Entfernung von Weich gewebesarkomen der Extremitäten und des Rumpfes. Handchir Mikrochir Plast Chir 47(02):128-133

46. Lagrange JL, Ramaioli A, Chateau MC et al (2000) Sarcoma after radiation therapy: retrospective multiinstitutional study of 80 histologically confirmed cases. Radiology 216:197-205

47. Lalam RK, Cassar-Pullicino VN, Tins BJ (2007) Magnetic resonance imaging of appendicular musculoskeletal infection. Top Magn Reson Imaging 18:177-191

48. Laskin WB, Silverman TA, Enzinger FM (1988) Postradiation soft tissue sarcomas: an analysis of 53 cases. Cancer 62:2330-2340

49. Liu CY, Yen CC, Chen WM et al (2010) Soft tissue sarcoma of extremities: the prognostic significance of adequate surgical margins in primary operation and reoperation after recurrence. Ann Surg Oncol 17:2102-2111

50. Liu PT, Leslie KO, Beauchamp CP, Cherian SF (2006) Chronic expanding hematoma of the thigh simulating neoplasm on gadolinium-enhanced MRI. Skeletal Radiol 35:254-257

51. Magerkurth Oetal (2015)MRimaging appearances of soft tissue flaps following reconstructive surgery of the lower extremity. Korean J Radiol 16(1):160-168

52. Maretty-Nielsen K et al (2014) Prognostic factors for local recurrence and mortality in adult soft tissue sarcoma of the extremities and trunk wall. Acta Orthop 85(3):323-332

53. Moore K et al (2009) Radiation-induced pseudotumor following therapy for soft tissue sarcoma. Skeletal Radiol 38:579-584

54. Murphey MD et al (2005) Radiographics 25:1371-1395

55. Nagano $S$ et al (2014) Analysis of surgical site infection after musculoskeletal tumor. Surgery: risk assessment using a new scoring system. Sarcoma. https://doi.org/10.1155/2014/645496

56. Nakamura (2013) Oncological outcome of patients with deeply located soft tissue sarcoma of the pelvis: A follow up study at minimum 5 years after diagnosis. Eur J Surg Oncol 39(9):1030-1035

57. National Comprehensive Cancer Network (2017) NCCN Clinical Practice Guidelines in Oncology (NC CN Guidelines ${ }^{\circledR}$ ). Soft Tissue Sarcoma. Version 2. https://www.nccn.org/professionals/physician_ gls/PDF/sarcoma.pdf.Zugegriffen:07.09.2017

58. Noebauer-Huhmann (2014) Weichteiltumoren. Radiologe 54(8):803-818

59. Noebauer-Huhmann IM, Weber MA, Lalam RK, Trattnig S, Bohndorf K, Vanhoenacker F, Tagliafico A, van Rijswijk C, Vilanova JC, Afonso PD, Breitenseher M, Beggs I, Robinson P, de Jonge MC, Krestan C, Bloem JL (2015) Soft tissuetumors in adults: ESSR-approved guidelines for diagnostic imaging. Semin Musculoskelet Radiol 19(05):475-482

60. Novais EN, Demiralp B, Alderete J, Larson MC, Rose PS, Sim FH (2010) Do surgical margin and local recurrence influence survival in soft tissue sarcomas? Clin Orthop Relat Res 468:3003-3011

61. al O'Connellet (1995) Intramuscular hypertrophic scar: an unusual complication following soft tissue sarcoma resection. Skeletal Radiol 24:305-307

62. Oka (2008) Ability of diffusion-weighted imaging for the differential diagnosis between chronic expanding hematomas and malignant soft tissue tumors. J Magn Reson Imaging 28(5):1195-1200

63. O'Sullivan B, Davis AM, Turcotte R et al (2002) Preoperativeversus postoperative radiotherapy in softtissuesarcoma of the limbs: a randomised trial. Lancet 359:2235-2241

64. O'Sullivan B, Davis A, Turcotte R et al (2004) Fiveyear results of a randomized phase III trial of pre-operative vs post-operative radiation therapy in extremity soft tissue sarcoma. J Clin Oncol 22(14_suppl):9007-9007

65. Panicek DM, Schwartz LH, Heelan RT, Caravelli JF (1995) Non-neoplastic causes of high signal intensity at T2-weighted MR imaging after treatment for musculoskeletal neoplasm. Skeletal Radiol 24(3):185-190

66. Park Sun-Young (2016) Comparison of MRI and PET-CT in detecting the loco-regionalrecurrence of soft tissue sarcomas during surveillance. Skeletal Radiol 45(10):1375-1384

67. Parrett BM, Talbot SG, Pribaz JJ, Lee BT (2009) A review of local and regional flaps for distal leg reconstruction. J Reconstr Microsurg 25:445-455
68. Patel (2017) Ann Surg Oncol 24(6):1588-1595

69. Patel SR (2000) Radiation-induced sarcoma. Curr Treat Options Oncol 1(3):258-261

70. Peat BG, Bell RS, Davis A, O'Sullivan B, Mahoney J, Manktelow RT et al (1994) Wound-healing complications after soft-tissue sarcoma surgery. Plast Reconstr Surg 93:980-987

71. Peterson JJ et al (2003) Skeletal Radiol 32:493-503

72. Poon-Chue A, Menendez L, Gerstner MM, Colletti P, Terk M (1999) MRI evaluation of post-operative seromas in extremity soft tissue sarcomas. Skeletal Radiol 28:279-282

73. Radtke C, Vogt PM (2014) Vogt Nervenverletzungen und posttraumatische Versorgung. Unfallchirurg 117(6):539-556

74. Reid JD, Kommareddi S, Lankerani M, Park MC (1980) Chronic expanding hematomas. A clinicopathologicentity.JAMA244(21):2441-2442

75. Richardson ML, Zink-Brody GC, Patten RM et al (1996) MR characterization of post-irradiation soft tissue edema. Skeletal Radiol 25(6):537-543

76. Van Rijswijk CSP, Bloem JL (2017) Follow-up imaging of soft tissuetumors. In: Vanhoenacker FM, Parizel PM, Gielen JL (Hrsg) Imaging of soft tissue tumors, 4. Aufl. Springer, Heidelberg, Berlin, New York

77. Sabolch A, Feng M, Griffith K et al (2012) Risk factors for local recurrence and metastasis in soft tissue sarcomas of the extremity. Am J Clin Oncol 35:151-157

78. Salas S, Stoeckle E, Collin F et al (2009) Superficial Soft Tissue Sarcomas (SSTS): a study of 367 patients from the French Sarcoma Group (FSG) database. Eur JCancer 45:2091-2102

79. Sampath S, Hitchcock YJ, Shreive DC et al (2010) Radiotherapy and extent ofsurgical resection in retroperitoneal soft-tissue sarcoma: multiinsitutionalanalysis of 261 patients. J Surg Oncol 101:341-350

80. Shapeero (2002) Clin Orthop Relat Res 397:212-227

81. Shapeero et al (2009) Post-treatment complications of soft tissue tumours. Eur J Radiol 69(2):209-221

82. Sheppard DG, Libshitz HI (2001) Post-radiation sarcomas: a review of the clinical and imaging features in 63 cases. Clin Radiol 56(1):22-29

83. Singer Set al (2003) Ann Surg 238(3):358-371

84. Soldatos (2012) Magnetic resonance Imagingof musculoskeletal infections. Acad Radiol 19:1434-1443

85. Stevens et al (1990) Early and late bone-marrow changes after irradiation: MR evaluation. AJR Am J Roentgenol 154:745-750

86. Tagliafico A, Truini M, Spina B et al (2015) Followup of recurrences of limb soft tissue sarcomas in patients with localized disease: performance of ultrasound. Eur Radiol 25(9):2764-2770

87. Tateishi T et al (2003) Primary dedifferentiated liposarcoma of the retroperitoneum prognostic significance of computed tomography and magnetic resonance imaging features. J Comput Assist Tomogr 27(5):799-804

88. Trovik CS, Bauer HC, Alvegard TA et al (2000) Surgical margins, local recurrence and metastasis insoft tissue sarcomas: 559 surgically-treated patientsfrom the Scandinavian Sarcoma Group Register. Eur JCancer 36(6):710-716

89. Vanel D, Lacombe MJ, Couanet D, Kalifa C, Spielmann M, Genin J (1987) Musculoskeletal tumors: follow-up with MR imaging after treatment with surgery and radiation therapy. Radiology 164:243-245 
90. Vanel D, Shapeero LG, De Baere T et al (1994) MR imaging in the follow-up of malignant and aggressive soft-tissue tumors: results of 511 examinations. Radiology 190:263-268

91. Vanel D, Shapeero LG, Tardivon A, Western A, Guinebretiere JM (1998) Dynamic contrastenhanced MRI with subtraction of aggressive soft tissue tumors after resection. Skeletal Radiol 27:505-510

92. Vanhoenacker FM, Van Looveren K, Trap K et al (2012) Grading and characterization of soft tissue tumors on magnetic resonance imaging: the value of an expert second opinion report. Insights Imaging 3(2):131-138

93. Whooley BP, Gibbs JF, Mooney MM, McGrath BE, Kraybill WG (2000) Primary extremity sarcoma: what is the appropriate follow-up? Ann Surg Oncol $7(1): 9-14 z$

94. Wolford LM et al (2003) Considerations in nerve repair. Proc (Bayl Univ Med Cent) 16:152-156

95. Woll PJ et al (2012) Adjuvant chemotherapy with doxorubicin, ifosfamide, and lenograstim for resected soft-tissue sarcoma (EORTC 62931): a multicentre randomised controlled trial. Lancet Oncol 13(10):1045-1054.https://doi.org/10.1016/ S1470-2045(12)70346-7

96. Wortman (2016) Radiation therapy for soft-tissue sarcomas: a primer for radiologists. Radiographics 36(2):554-572
97. Zagars GK, Ballo MT, Pisters PW et al (2003) Prognostic factors for patients with localized softtissue sarcoma treated with conservation surgery and radiation therapy: an analysis of 1225 patients. Cancer 97(10):2530-2543

98. Zagars GK, Ballo MT, Pisters PW, Pollock RE, Patel SR, Benjamin RS (2003) Preoperative vs. postoperative radiation therapy for soft tissue sarcoma: a retrospective comparative evaluation of disease outcome. Int J Radiat Oncol Biol Phys 56(2):482-488

99. Zagars GK, Ballo MT, Pisters PW et al (2003) Prognostic factors for disease-specific survival after first relapse of soft-tissue sarcoma: analysis of 402 patients with disease relapse after initial conservative surgery and radiotherapy. Int J Radiat Oncol Biol Phys 57:739-747

\section{e.Med Radiologie Das Fortbildungs-Abo passend zu Ihrem Fachgebiet}

SpringerMedizin.de bietet allen Ärzten, die sich effizient auf dem Laufenden halten wollen, ein maßgeschneidertes Fortbildungs-Abo mit CME-Fortbildungen und Premium-Inhalten der Fachzeitschriften passend zu Ihrem Fachgebiet. Inklusive einer gedruckten Zeitschrift.

Gezielt recherchieren, schnell und aktuell informieren

Mit e.Med Radiologie erhalten Sie Zugriff auf die radiologischen Fachzeitschriften und die dazugehörigen Fortbildungen.

> Nutzen Sie unser umfangreiches Kursangebot aus der Radiologie, um sich fortzubilden und ganz einfach online CME-Punkte zu sammeln.

Profitieren Sie von der aktuellen und fundierten Berichterstattung über Entwicklungen und Neuheiten in der Radiologie.
Greifen Sie auf die Volltexte von deutschen und englischsprachigen radiologischen Fachzeitschriften zu - direkt auf der Website, als ePaper oder als PDF-Download.

Darüber hinaus ist im e.Med Radiologie Abo eine radiologische Springer Medizin Fachzeitschrift enthalten, die Ihnen regelmäßig per Post zugesandt wird.

Testen Sie e.Med Radiologie

30 Tage kostenlos und unverbindlich!

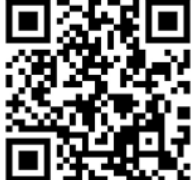

Jetzt informieren unter

http://bit.ly/2ii9A1N

oder telefonisch unter 0800-77 80777

(Montag bis Freitag, 10 bis $17 \mathrm{Uhr}$ ) 